\title{
AMBIENTES DE APRENDIZAJE
}

\section{LEARNING ENVIRONMENTS}

\author{
Raquel Inés Bouvet de Korniejczuk \\ Universidad de Montemorelos, México \\ rkorniej@um.edu.mx
}

\begin{abstract}
RESUMEN
Reseña de un libro: Krumm, S. (2018). Ambientes de aprendizaje: educación integral en entornos favorables. Buenos Aires: ACES.

Palabras clave: ambiente de aprendizaje, didáctica

\section{ABSTRACT}

Book review: Krumm, S. (2018). Ambientes de aprendizaje: educación integral en entornos favorables [Learning environments: integral education in favorable environments]. Buenos Aires: ACES
\end{abstract}

Keywords: learning environment, teaching

Ambiente de aprendizaje: educación integral en entornos favorables es un libro que parece un diálogo íntimo docente-docente: una docente con una rica experiencia en todos los niveles educativos (inicial a posgrado) inicia una conversación con un docente, sin importar su experiencia y nivel.

Al leer el libro el lector puede imaginarse haber entrado en el aula de la autora: de curiosidad, de profundidad, de sorpresa, de actividad, de reflexión, de ideas y de aprendizajes fáciles y alegres. Es que, quienes conocen a Sonia Krumm saben que es una docente exuberante en ideas, recursos, motivación e inspiración para sus estudiantes y colegas.

Basada en su propia trayectoria docente, la autora dice que "el aprendizaje es un proceso tan complejo y único como el ambiente en el que se da. Comprenderlo es una manera de intentar que cada factor en juego y cada esfuerzo se optimicen" (p. 9). Con esas palabras introduce su obra, que lleva al lector de la reflexión a la práctica áulica.

Para que el lector vivencie las distintas facetas del ambiente de aprendizaje, la autora ingenia maneras novedosas: un diseño gráfico desestructurado que genera cercanía con el lector y diversas actividades interactivas como propuestas de discusión, espacios para reflexionar, sugerencias de libros y películas para leer y observar, ilustraciones provocativas, cuadros para leer y comparar, propuestas de evaluación, ejemplos, lluvia de ideas y juegos. Pero el libro es más que un compendio de sugerencias que disparan la propia creatividad del lector, porque provee de un fundamento sólido para cada uno de los conceptos que presenta en el texto y una bibliografía que lo sustenta al final de cada capítulo. 
Ambiente de aprendizaje es un libro de didáctica con una perspectiva innovadora. Es una obra que mira la complejidad de la educación desde una sólida perspectiva bíblica, no solo para mirar al conocimiento con los lentes de Dios, sino para plantear a la educación como un proceso que va mucho más allá de los aprendizajes intelectuales, ya que rescata la importancia del funcionamiento saludable del cuerpo para aprender y los valores espirituales en el desarrollo integral del cuerpo, la mente y el espíritu.

Aunque es un libro de didáctica, el protagonista del libro no es el maestro o el alumno - actores tradicionales de los libros de didáctica-, sino es el ambiente. $\mathrm{Y}$ el ambiente propicio para el aprendizaje, presentado por la autora en sus distintas facetas, surge de las acciones de la institución, del maestro y del alumno. De modo que, sin mencionarlo explícitamente, el lector puede identificar fácilmente el rol didáctico del maestro, el aporte del alumno y la administración del acto pedagógico por parte de una institución educativa.

En el corazón del libro, en los capítulos 4, 5, 6 y 7, está desarrollada la tesis principal de la obra: la educación más valiosa consiste en desarrollar la facultad de pensar y de hacer. Una tesis que presentó Elena de White en 1903 y que es una premisa verdadera. Esta obra recrea, amplía y actualiza la tesis de White ejemplificada con múltiples ideas para que se potencien en la escuela. Da por cierto que toda propuesta educativa parte de una comprensión del ser humano y del mundo y propone el ideal para el ser humano. La obra presenta que enseñar a pensar en la escuela no parte de una cosmovisión neutral, sin valores ni principios. Es por eso que enseñar valores es importante, pero más importante que los valores es la fuente de los valores elegidos.

El aprendizaje comienza con las ganas de pensar, el deseo de aprender de un alumno (y de un maestro, ipor qué no!). Quien hace la magia de encender los motores, según Krumm, es el maestro, quien con estrategias promueve el desarrollo integral y la conexión con el mundo real. Así se desarrollan los procesos cognitivos, metacognitivos y el traslado a la vida real en la resolución de problemas en situaciones controladas por la escuela y en las circunstancias de la vida cotidiana que sorprenden a todos.

La originalidad de este libro radica en la valorización del ambiente de aprendizaje desde una perspectiva integral. Aunque los ejemplos propuestos por la obra están dirigidos fundamentalmente a maestros de educación inicial y básica, docentes de educación superior encontrarán pensamientos provocadores que dispararán sus propias ideas innovadoras.

Este es un libro que no solo es útil para la reflexión. También mueve al lector a la acción, a probar nuevos enfoques en las aulas y hasta tiene la invitación de compartir los hallazgos con la autora. Recomiendo que se lea el libro con un lápiz y un papel para anotar los pensamientos provocadores y las ideas de trascendencia a las situaciones áulicas del lector. Así el lector puede construir su propio ambiente de aprendizaje. 